\title{
Intraspecific dietary variation in the short-beaked common dolphin Delphinus delphis in the Bay of Biscay: importance of fat fish
}

\author{
Laureline Meynier ${ }^{1, *}$, Claire Pusineri ${ }^{2}$, Jérôme Spitz ${ }^{1}$, M. Begoña Santos ${ }^{3,4}$, \\ Graham J. Pierce $^{3}$, Vincent Ridoux ${ }^{1,2}$
}

${ }^{1}$ Centre de Recherche sur les Mammifères Marins, and ${ }^{2}$ Centre de Recherche sur les Ecosystèmes Littoraux Anthropisés, Unité Mixte de Recherche (U.M.R.) 6217, Université de La Rochelle, 23 Avenue Albert Einstein, 17071 La Rochelle cedex, France

${ }^{3}$ School of Biological Sciences, University of Aberdeen, Tillydrone Avenue, Aberdeen AB24 2TZ, UK

${ }^{4}$ Instituto Español de Oceanografía, Centro Costero de Vigo, Cabo Estay, Canido, 36208, Vigo, Spain

\begin{abstract}
Investigations of trophic interactions between marine mammals and marine resources typically use trophic models that are based on food composition, energy content of the prey and energy requirements of the predators. Although the diets are known to vary intraspecifically according to year, season, sex and age, this variation is rarely taken into account in published models. The aim of the present study was to assess the diet of the short-beaked common dolphin Delphinus delphis in the Bay of Biscay (France), examine intraspecific dietary variation and explore its effects on calculated daily food intake. Stomach contents were analysed from 71 common dolphins stranded along the French coast between 1999 and 2002. The composition of the fresh fraction of the diet was quantified by occurrence, relative abundance, reconstructed mass and prey size distributions for all prey taxa. Overall, the most important prey species were sardine, anchovy, sprat and horse mackerel, which represented 44.9, 22.6, 8.0 and $5.0 \%$ by mass of the fresh diet, respectively. The diet composition displayed significant variation in relation to season and sex/maturity status, in terms of both prey species composition and prey size distributions. Temporal variation in diet composition was interpreted in relation to prey availability in the Bay of Biscay. Because different prey types have different energetic values, changes in diet composition could lead to changes in the estimated total biomass needed to fulfil energetic requirements. In spite of the main prey species varying extensively, estimated daily food intakes changed relatively little because all diets included a high proportion of fat fish (73 to $93 \%$ by mass).
\end{abstract}

KEY WORDS: Diet · Delphinus delphis $\cdot$ Common dolphin $\cdot$ Energy requirements $\cdot$ Prey availability Stomach content analysis

\section{INTRODUCTION}

Marine mammals are frequently regarded as competitors by humans as they generally feed at trophic levels similar to those occupied by fisheries. Their role in the marine ecosystem has received increasing attention by fisheries scientists throughout the past $20 \mathrm{yr}$, during which time many consumption models have been developed. In this context, the diets and feeding habits of marine mammals are key data in assessing their impact on marine stocks. When modelling annual takes of resources by a population of marine mammals, the composition by mass of the diet is often considered to be constant over time and among the different segments of the population (e.g. Hammill \& Stenson 2000, Bjørge et al. 2002). 
However, variation in dietary compositions of cetaceans exist and may have different causes, including differential foraging tactics among different segments of the population or spatiotemporal heterogeneity in prey availability (e.g. Young \& Cockcroft 1994, Santos et al. 2004a,b for cetaceans; Brown et al. 2001, Page et al. 2005 for pinnipeds). One may expect some degree of ontogeny in foraging abilities as a consequence of the development of sensorial, swimming and diving performances. For similar reasons, highly dimorphic species could also display sex-related differences in diet composition, and females associated with nursed calves could modify their diet either to face the increased energetic demand or as a response to the limited physical performance of their calf. Seasonal patterns in prey availability are mostly related to the recruitment of juveniles in prey populations. However, the energetic costs and benefits of foraging could be more dependent on factors such as prey aggregation or changes in energy density. Many potential prey species show seasonal changes in their distribution patterns and aggregate on spawning and feeding grounds or migratory routes. Additionally, prey body composition and energy content change markedly as a result of gonadal activity. Hence, predators could seasonally switch from one key species to another according to such temporary opportunities.

Whatever the causes of dietary variation, such changes would have effects on the composition and the yearly total amount of food consumed by a population. Indeed, the combination of specific diets of each season and/or each population segment determines the annual diet. Intraspecific dietary changes could, indirectly (because prey taxa differ in body composition and energy content), induce seasonal and age- or sex-related differences in the average food energy density and, hence, total food intake.

So far, few studies have shown the effect of temporal and demographic factors on dietary composition in small cetaceans. Annual and seasonal dietary variation has been documented for the short-beaked common dolphin Delphinus delphis (Bay of Biscay, Desportes 1985; Galician waters, Santos et al. 2004a) and for the harbour porpoise (Scotland, Santos et al. 2004b). Young \& Cockcroft (1994) considered the combined effect of sex and maturity on the diet of the common dolphin off South Africa. Santos et al. (2004a,b) also found variation in the diet of common dolphins and harbour porpoises in relation to predator length.

The short-beaked common dolphin is one of the most widely distributed cetaceans, inhabiting all temperate, subtropical and tropical seas (Evans 1994). It feeds mainly on small pelagic shoaling fish, and also some cephalopods (Young \& Cockcroft 1994, Santos et al. 2004a). In the Bay of Biscay, horse mackerel Trachurus spp., gadids of the genus Trisopterus, and blue whiting Micromesistius poutassou were the prevalent prey types found in stranded dolphins in the early 1980 s (Desportes 1985).

The aim of the present study was to assess the diet of the common dolphin in the Bay of Biscay, to investigate intraspecific dietary variation to explore its potential effects on estimates of the consumed prey biomass. Although ecological indicators such as stable isotopes and fatty acids proved to be extremely powerful tools in many recent studies in the feeding ecology of marine top predators, they are not designed to quantify prey species composition in small delphinids; therefore, in the present study we rely solely on stomach content analysis.

\section{MATERIALS AND METHODS}

Sampling. A total of 71 stomach content samples were collected from common dolphins found stranded along the French coast of the Bay of Biscay from 1999 to 2002 (Fig. 1). Three categories of stranding were defined (Centre de Recherche sur les Mammifères Marins [CRMM] pers. comm.): (1) mass stranding (one social unit gets stranded alive during a single event); (2) multiple stranding (several 10s of individuals are found beach-cast over a period of a few weeks in the

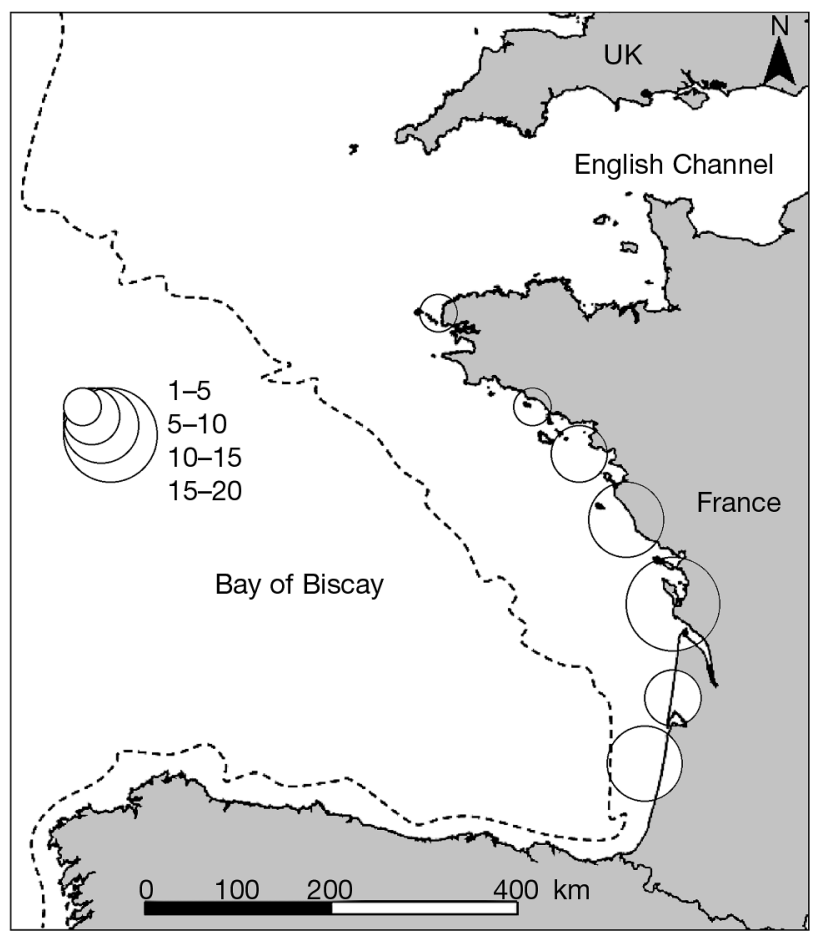

Fig. 1. Location and number of strandings of common dolphins analysed. (---): upper limit of the continental slope 
same region, generally as a result of a single cause of death); and (3) single stranding ('background' stranding occurring year-round, due to a combination of causes of death, either natural or man-induced). The present study has been limited to dolphins collected during single stranding events, as they are likely to encompass a broader variety of origins (geographical, temporal, causes of death, etc.) than the other categories and ensure a higher level of independence between individual samples.

Whole stomachs were removed and stored at $-20^{\circ} \mathrm{C}$ in polyethylene bags until further analyses. Dolphins were classified into 3 categories: immature individuals, mature females and mature males. At the time of the analysis, information on the reproductive status and age of several of the individuals were not available; thus, we based our classification on the length of the dolphin: mature specimens were considered to be those $>2 \mathrm{~m}$ for males and $>1.90 \mathrm{~m}$ for females (Collet 1981).

Analyses. Stomach contents were thawed and washed through a sieve of $0.2 \mathrm{~mm}$ mesh size; loose diagnostic parts (fish bones, otoliths and cephalopod beaks) and fresh prey items were recovered and identified by using published guides (Clarke 1986, Härkönen 1986). Fish bones and otoliths were stored dry, whereas cephalopod beaks were kept in $70 \%$ ethanol. To minimize overestimation of the relative importance of prey whose remains are resistant to digestion, each prey item was scored on a scale according to its degree of digestion. This allowed us to determine a fresh fraction that would better represent the composition of the ingested prey than a total diet composition derived from all prey items (Pusineri et al. 2007). The number of individuals was determined as half the number of otoliths rounded up to the integer for fish and as the maximum number of lower or upper beaks for cephalopods (Pierce \& Boyle 1991). Diagnostic hard parts were measured $( \pm 0.02 \mathrm{~mm})$ following standards (Clarke 1986, Härkönen 1986). When more than 50 diagnostic remains were present for one prey taxon in a stomach, a sub-sample of 30 was measured. Individual prey body length and mass were calculated using regressions from the literature (Bedford et al. 1986, Clarke 1986, Härkönen 1986, Coull et al. 1989) or from our reference collection.

The frequency of occurrence of a given prey taxon was calculated as the number of stomachs in which the taxon was observed. The relative abundance was assessed as the number of items found in the sample set. The reconstructed biomass was calculated as the product of the number of individuals and the average reconstituted body mass, in each stomach, summed throughout the sample set. Prey size distributions at sample level were weighted by the number of individ- uals in the sample and summed to produce the overall size distribution of a prey species in the whole series of samples. Sampling errors were assessed by generating non-parametric 95\% confidence intervals around percentage number and mass using bootstrap simulations (Reynolds \& Aebischer 1991). The bootstrapping routine was written using $\mathrm{R}$ ( $\mathrm{R}$ Development Core Team 2005); random samples were drawn with replacement and the procedure was repeated 1000 times.

Intraspecific diet variability. The factors 'season' and combined 'sex/maturity' were tested to look at dietary variation among the sample set. The ScheirerRay-Hare test (SRH test) (equivalent to a non-parametric 2-way ANOVA with replication, Dytham 1999) was applied on prey number per stomach for the main prey species (occurrence $>20 \%$ ). The reconstructed mass was not tested as it is subject to more errors than number (back calculated from hard part measurements). The tested groups were winter (W), spring (Sp), summer and autumn (SuA); and immatures (Im), mature females (MaF) and mature males (MaM). Summer and autumn were grouped, as they were not represented in each 'sex/maturity' category. We did not test size distribution in order to avoid pseudo-replication, since individual fishes of the same species from a single stomach are not independent samples. Instead, we tested the median size by using the Kruskal-Wallis test. Post-hoc comparisons were made by using the Mann-Whitney U-test. Lastly, a Spearman's rank correlation was used on dolphins and prey lengths to assess any correlation between these 2 variables.

In order to examine the importance of dietary variation in estimating food consumption, a relative individual daily consumption was calculated from energy requirements (Kleiber 1975), prey energy content (see Table 4 for references) and prey composition by percent mass as follows:

$$
\begin{aligned}
C_{i}= & P_{i} I \text { with } I \approx(3 \mathrm{BMR}) / \Sigma\left(P_{i} C V_{i}\right) \\
& =\left[3(293) M^{0.75}\right] / \Sigma\left(P_{i} C V_{i}\right)
\end{aligned}
$$

where $C_{i}$ is the relative daily consumption of prey $i(\mathrm{~kg}$ $\left.\mathrm{d}^{-1}\right)_{i} P_{i}$ is the proportion by mass of prey species $i$ in the diet (fresh fraction); $I$ is the relative daily consumption of a dolphin; the activity metabolic rate $\left(\mathrm{kJ} \mathrm{d}^{-1}\right)$ is assumed to be about 3 times basal metabolic rate (BMR) (from Young \& Phillips 2002, data for bottlenose dolphins); $M$ is the average predator body mass (kg), set here at $90 \mathrm{~kg}$ irrespective of age and sex because the aim of the present study was to assess the effect of dietary variation on the estimation of food intake and not the relationship between individual body mass and food intake; and $C V_{i}$ is the calorific value of prey $i$ ( $\mathrm{kJ} \mathrm{kg}^{-1}$ wet mass). Because there is no assimilation rate (AR) known for this species, we did not incorpo- 
rate $\mathrm{AR}$ in the calculation; as a consequence the relative daily ration calculated here is an underestimation of the true value. This was not critical in the present study as only variation of the daily food intake was of interest here.

\section{RESULTS}

Immatures represented more than half the total of individuals (Table 1). Mature females and males were in similar numbers. Most of the samples were collected in winter, which is the only season with a good representation of immature dolphins and mature females and males.

\section{Overall diet composition}

Fish dominated the fresh fraction of the diet (Table 2), accounting for $84.2 \%$ of the diet by number and $94.4 \%$ by mass, and occurring in all stomachs but one. Cephalopods ranked a distant second in importance, whereas crustaceans were merely incidental. A total of 5847 individual prey were retrieved. Four prey taxa appeared in more than $40 \%$ of the stomachs: gobies, anchovy, sardine and sepiolids. Gobies made up $42.2 \%$ of the diet by number, but their contribution to the total mass was only about $2.5 \%$ due to their very small individual size (mean $\pm 1 \mathrm{SE} ; 0.7 \pm 0.4 \mathrm{~g}$ ). Anchovy represented $23.3 \%$ number and $22.6 \%$ mass; sardine had a rather low contribution by number $(6.3 \%)$, but was dominant by reconstructed biomass $(44.9 \%)$ as a result of its comparatively larger average body size $(81.7 \pm 34.3 \mathrm{~g})$. Horse mackerel and sprat occurred in more than $20 \%$ of the stomachs and were the most important prey by mass (5.0 and 8.8\%, respectively) after sardine and anchovy.

Species-specific average length of prey taken ranged from $2.1 \pm 0.1 \mathrm{~cm}$ (Sepiolidae) to $29.0 \pm 7.7 \mathrm{~cm}$ (mackerel) (Table 2); however, 3 garfishes found in the same stomach had a body length of $60.8 \pm 7.3 \mathrm{~cm}$. High $\mathrm{SE}$ in length and mass estimations for most prey cate-

Table 1. Delphinus delphis. Distribution of the number of stomachs analysed in relation to seasons and sex/maturity status. Im: immature dolphins; MaF: mature females; MaM: mature males

\begin{tabular}{|lrrccc|}
\hline & Winter & Spring & Summer & Autumn & Total \\
\hline Im & 20 & 10 & 6 & & 36 \\
MaF & 8 & 1 & 1 & 3 & 13 \\
MaM & 8 & 2 & & 2 & 12 \\
Total & 36 & 13 & 7 & 5 & 61 \\
\hline
\end{tabular}

gories (blue whiting, hake, mackerel and sand eel) are due to high variation in prey size between and among individual dolphins, probably indicating the presence of several age classes for the corresponding prey species. When pooling all prey species together, the major size classes were from 10 to $22 \mathrm{~cm}$ and modal individual mass was less than $20 \mathrm{~g}$.

The diet composition of the total stomach contents (uncorrected for the different digestion rates; Table 2) is necessary for comparing the present work with other studies. Only a few prey categories were missing from the fresh stomach contents but present in total contents: silvery pout, rocklings, whiting and squid of the family Ommastrephidae. However, several fish species were more frequently represented from hard remains than fresh remains, notably horse mackerel, blue whiting and Trisopterus spp.

\section{Diet variability and its importance for estimating food intake}

Seasonal variation

Seasonal variation was examined on dietary data stratified into seasons (Fig. 2). Summer and autumn seasons were pooled for the use of the SRH test; thus, differences were tested between 3 periods: winter, spring and summer/autumn. Sardine was the dominant prey by mass in summer/autumn and winter (47 and $59 \%$, respectively); its contribution was slightly lower in spring although not significantly so (Table 3A, $\left.F_{2}=0.51, \mathrm{p}=0.60\right)$. Sprat showed the reverse trend. Anchovy did not show any marked variation (Fig. 2); however, the tests revealed that females in the summer/autumn ate more of this prey $\left(F_{2}=2.86, \mathrm{p}=0.03\right)$. Horse mackerel was absent in the summer and the amounts found in spring and summer/autumn were significantly higher than in the winter (Table 3A, Fig. $2 ; F_{2}=7.82, \mathrm{p}<0.01$ ). Gobies were the most important prey by number from the winter to the summer $(\sim 30 \%)$. The large contribution by mass of mackerel in the summer is due to larger mackerels, but this involves only 3 stomach samples. No significant difference by size was found for the main prey (Table 3B).

\section{Variation between sex and maturity stages}

The prey composition of mature males was less diversified (9 taxa) than the diet of mature females (15 taxa) and immature dolphins (21 taxa): there was notably a lack of sprat and cephalopods and a high dominance of sardine (80\% mass) (Fig. 2). Also, the amount of horse mackerel was significantly lower in 


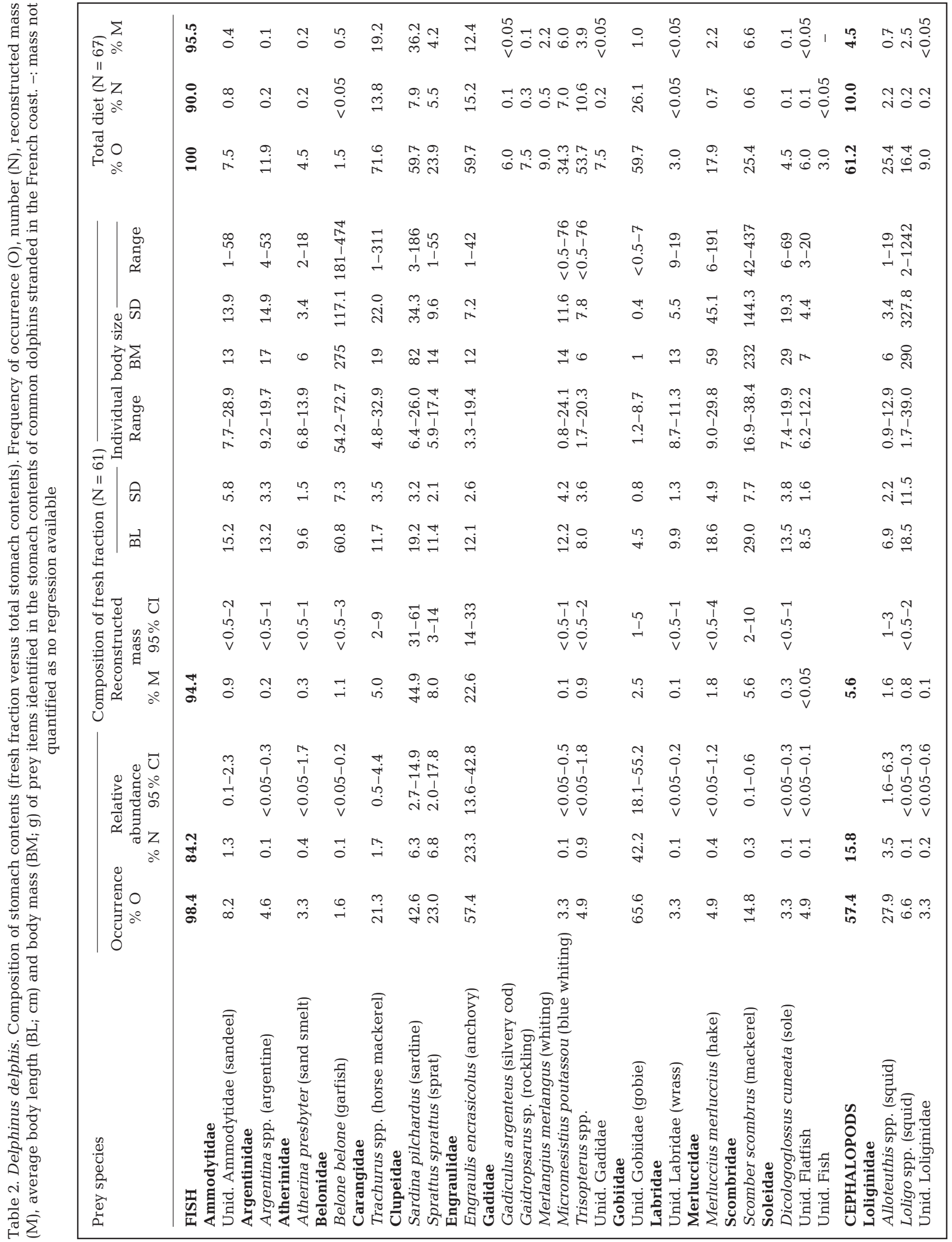




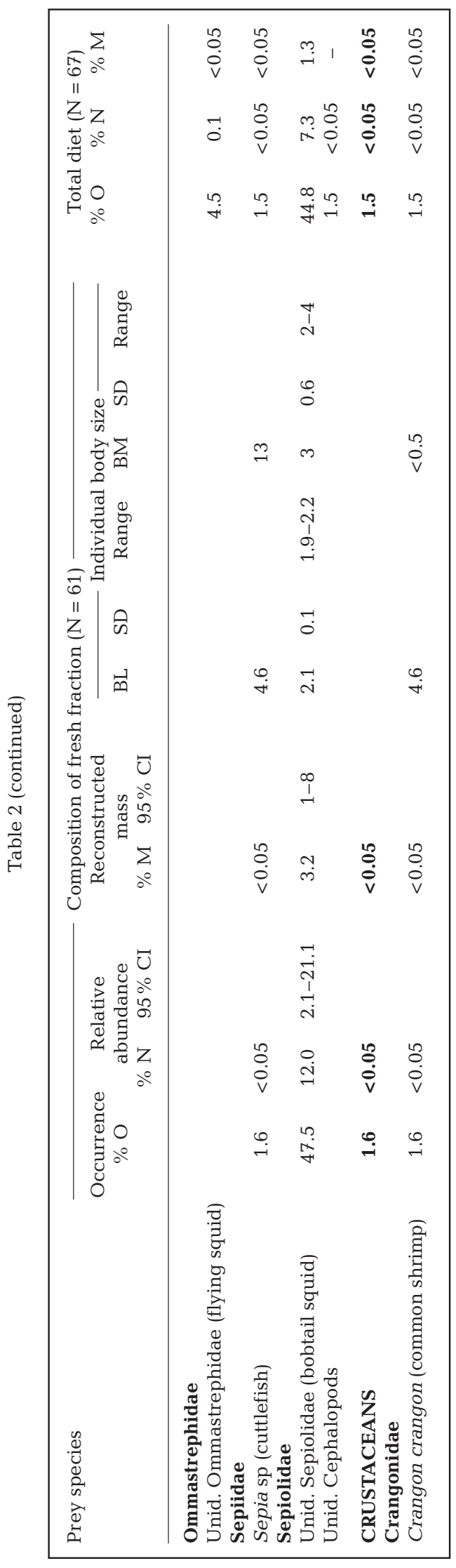

immature individuals than in adults for all seasons except winter (Table $3 \mathrm{~A}_{;} F_{4}=3.53, \mathrm{p}=0.01$ ). Regarding prey size, adult males fed on larger sardine than mature females and immature dolphins did (Table 3B; $\left.H_{2}=6.42, \mathrm{p}=0.04\right)$ and immature dolphins ate smaller horse mackerels than adult females (Table $3 \mathrm{~B}_{;} \mathrm{H}_{2}=$ $8.35, p=0.02)$. Overall, prey length was weakly correlated to dolphin length (Fig. $3 ; \mathrm{r}=0.34$, df $=3454$ ).

\section{Effect of dietary changes on calculation of food intake}

From the reference diet composition, i.e. all samples combined, the daily food intake was estimated at $2.93 \mathrm{~kg} \mathrm{~d}^{-1}$ (Table 4) of which sardine made up $1.32 \mathrm{~kg} \mathrm{~d}^{-1}$, anchovy $0.61 \mathrm{~kg} \mathrm{~d}^{-1}$ and sprat $0.26 \mathrm{~kg} \mathrm{~d}^{-1}$. Horse mackerel, mackerel and cephalopods each represented less than $0.20 \mathrm{~kg} \mathrm{~d}^{-1}$. The fat fish, sardine, sprat, anchovy and mackerel, jointly contributed to $80 \%$ of the mass ingested per day and, because of their higher energy content, as much as $89 \%$ of the energy provided to the predator.

Regarding differences between sexes and maturity classes (Table 4), sardine and anchovy were consumed by each category in amounts varying from 0.83 to 2.19 and 0.31 to $0.94 \mathrm{~kg} \mathrm{~d}^{-1}$, respectively. More specifically, cephalopods were nearly absent in the diet of mature males, which ate only 4 different prey species of high calorific value, leading to the lowest total daily food consumption with only $2.76 \mathrm{~kg} \mathrm{~d}^{-1}$. However, the extensive differences observed in dietary composition between sex and maturity categories affected average energy content of the food to a much more limited extent, because the core of the diet always consisted of energy-rich fish (low coefficients of variation, CV). The dietary pattern changed even more markedly when considering seasonal dietary composition (Table 4). Sardine dominated the diet in the autumn and winter seasons, with estimated amounts of 1.41 and $1.73 \mathrm{~kg} \mathrm{~d}^{-1}$, respectively, against only $0.12 \mathrm{in}$ spring and 0.15 in the summer, a difference of one order of magnitude. Conversely, sprat was consumed mostly in the spring and summer seasons, and also showed extensive seasonal variation. Again, marked seasonal differences in food composition were not paralleled by similar changes in daily food intake, because the total contribution of fat fish to the daily ration remained elevated.

To conclude, in spite of these different sources of variation in daily consumption of individual prey species, the overall daily food intake did not change much, as indicated by CVs no larger than $5 \%$. This is explained by the fact that changes in dietary composition did not operate at random among all possible prey; 

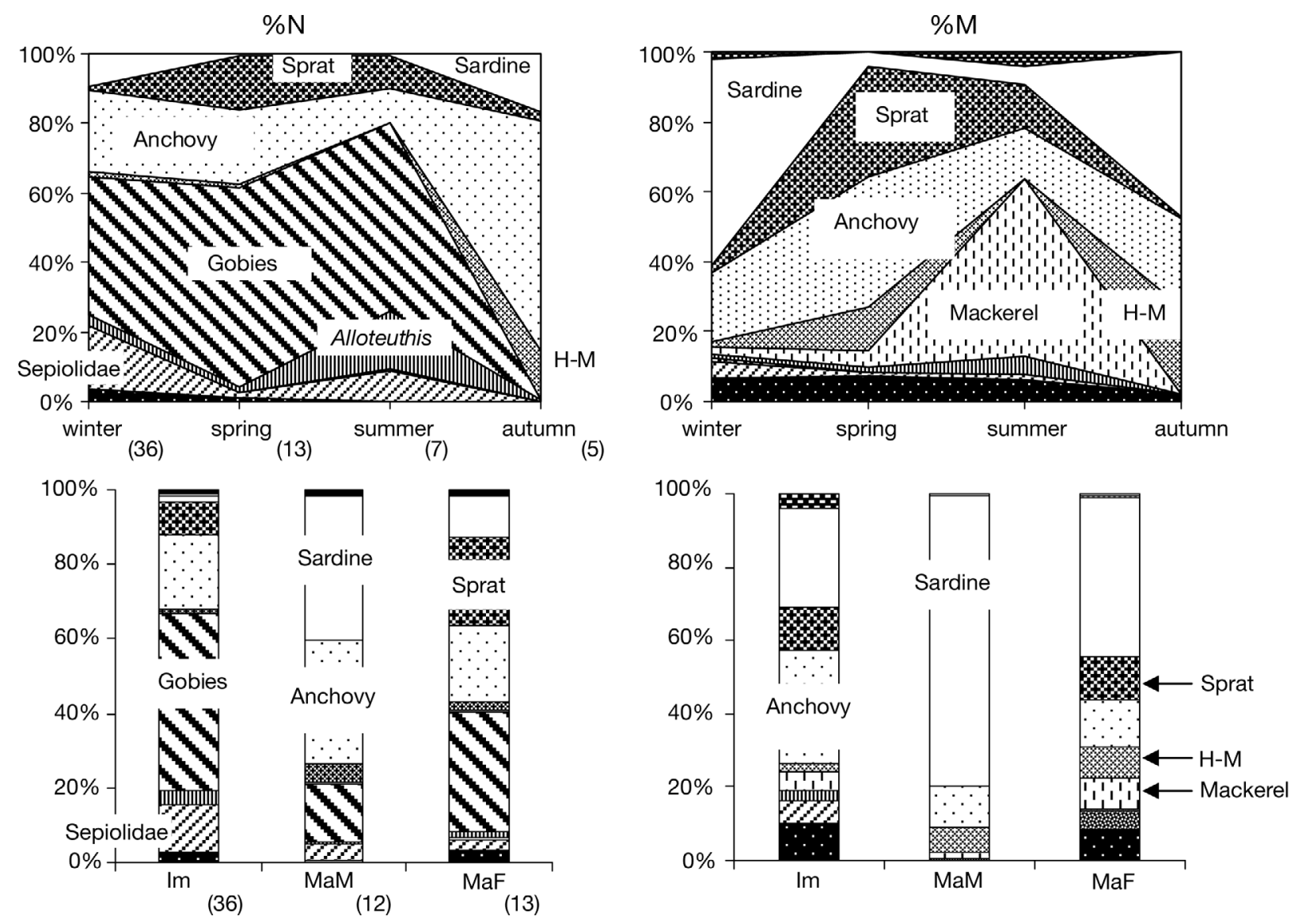

Fig. 2. Delphinus delphis. Diet composition according to season and sex/maturity status. Prey species comprising $<10 \%$ of the total are not labelled. \% N: percentage by number; \% M: percentage by mass; H-M: horse mackerel; Im: immature; MaM: mature males; MaF: mature females. The number of stomachs for each category is indicated in brackets

instead these changes operated at a fairly constant proportion of fat fish in the diet ( 73 to $93 \%$ mass), irrespective of the season and sex/maturity categories (Table 4).

\section{DISCUSSION}

The present study updated the information on the diet of the short-beaked common dolphin Delphinus delphis in the Bay of Biscay, collected in the 1980s (Desportes 1985), and provided quantification by mass, a key element for food consumption modelling. Also, this study revealed some diet variations between seasons, sex and maturity stages. The Bay of Biscay is an important fishing ground, where large populations of dolphins occur; however, limited information is available on habitat use, possible migration patterns or foraging areas. To date, no foraging study using satellite telemetry has been carried out on the common dolphin in the Bay of Biscay. However, by analysing the diet through stomach contents from stranded dolphins, it is possible to make limited yet useful inferences about foraging strategies. However, inferences on foraging habits by interpreting dietary results are often limited by the biases associated with dietary analysis methods. Firstly, stranded dolphins studied may have been sick or not independent from each other (belonging to the same group), raising concern as to the representativeness of data collected from stranded dolphins. We minimized these biases by analysing only dolphins collected during single stranding events (definition in 'Materials and methods') and by focusing on samples containing fresh food remains, suggesting that the dolphins were sufficiently healthy prior to death to forage efficiently. Secondly, stomach content analysis is classically based on the determination of prey hard parts, which accumulate to different degrees in the stomach, leading to an overestimation of some species. The effects of these biases were tentatively mitigated in the present study by considering the fresh fraction only in the analysis. 
Table 3. Delphinus delphis. (A) Scheirer-Ray-Hare results on number of prey; (B) Kruskal-Wallis results on median size of prey between groups of common dolphins defined by season $(\mathrm{W}=$ winter, $\mathrm{Sp}=$ spring, $\mathrm{SuA}=$ summer and autumn), and sex/maturity ( $\mathrm{Im}=$ immature dolphins, $\mathrm{MaM}=$ mature males, $\mathrm{MaF}=$ mature females). Significant statistical values are shown in bold $(\mathrm{p}<$ 0.05). \% O: percent occurrence; ${ }^{*}$ : only 2 categories were available

\begin{tabular}{|c|c|c|c|c|c|c|}
\hline \multirow[t]{2}{*}{$\begin{array}{l}\text { A } \\
\text { Prey type }\end{array}$} & \multicolumn{2}{|c|}{$\begin{array}{l}\text { Season } \\
(\mathrm{df}=2)\end{array}$} & \multicolumn{2}{|c|}{$\begin{array}{l}\text { Sex/maturity } \\
\quad(\mathrm{df}=2)\end{array}$} & \multicolumn{2}{|c|}{$\begin{array}{l}\text { Interaction } \\
\quad(\mathrm{df}=4)\end{array}$} \\
\hline & $F$ & $\mathrm{p}$ & $F$ & $\mathrm{p}$ & $F$ & $\mathrm{p}$ \\
\hline $\begin{array}{l}\text { Gobies } \\
(\% \mathrm{O}=65.6)\end{array}$ & 1.94 & 0.17 & 2.26 & 0.12 & 0.58 & 0.68 \\
\hline $\begin{array}{l}\text { Anchovy } \\
(\% \mathrm{O}=57.4)\end{array}$ & 1.14 & 0.33 & 1.79 & 0.18 & \multicolumn{2}{|c|}{$\begin{array}{c}\mathbf{2 . 8 6} \quad \mathbf{0 . 0 3} \\
\mathrm{MaF} \text { in } \mathrm{SuA}> \\
\text { others }\end{array}$} \\
\hline $\begin{array}{l}\text { Sepiolid } \\
(\% \mathrm{O}=47.5)\end{array}$ & 1.21 & 0.31 & 1.62 & 0.21 & 0.96 & 0.44 \\
\hline $\begin{array}{l}\text { Sardine } \\
(\% \mathrm{O}=42.6)\end{array}$ & 0.51 & 0.60 & 2.61 & 0.09 & 1.73 & 0.16 \\
\hline $\begin{array}{l}\text { Alloteuthis } \\
(\% \text { O = 27.9) }\end{array}$ & 0.20 & 0.82 & 1.49 & 0.24 & 1.11 & 0.36 \\
\hline $\begin{array}{l}\text { Sprat } \\
(\% \mathrm{O}=23.0)\end{array}$ & 2.57 & 0.09 & 2.41 & 0.10 & 0.60 & 0.66 \\
\hline $\begin{array}{l}\text { Horse mackerel } \\
(\% \mathrm{O}=21.3)\end{array}$ & $\begin{array}{l}7.82 \\
W<S\end{array}$ & $\begin{array}{l}<0.01 \\
\text { p, SuA }\end{array}$ & $\begin{array}{r}6.27 \\
\operatorname{Im}<1\end{array}$ & $\begin{array}{c}<\mathbf{0 . 0 1} \\
\mathrm{M}, \mathrm{MaF}\end{array}$ & $\begin{array}{r}3.53 \\
\text { Im in } \\
\text { ot }\end{array}$ & $\begin{array}{l}\mathbf{0 . 0 1} \\
\mathrm{SuA}< \\
\mathrm{rs}\end{array}$ \\
\hline \multicolumn{7}{|l|}{ B } \\
\hline \multirow[t]{2}{*}{ Prey type } & \multicolumn{4}{|c|}{ Season $(\mathrm{df}=2)$} & \multicolumn{2}{|c|}{ Sex/maturity $(\mathrm{df}=2)$} \\
\hline & & $H$ & $\mathrm{p}$ & & $H$ & $\mathrm{p}$ \\
\hline Anchovy & & 1.62 & 0.44 & & \multicolumn{2}{|c|}{$\mathrm{Im}<\mathrm{MaM}$} \\
\hline Sepiolid & & 0.31 & 0.86 & & 3.64 & 0.16 \\
\hline Sardine & & 5.19 & 0.08 & & \multicolumn{2}{|c|}{$\operatorname{Im}, \mathrm{MaF}<\mathrm{MaM}$} \\
\hline \multirow{2}{*}{$\begin{array}{l}\text { Sprat } \\
\text { Horse mackerel }\end{array}$} & & 3.01 & 0.22 & & \multicolumn{2}{|c|}{$0.68^{*}$} \\
\hline & & 5.02 & 0.08 & & $\mathrm{Im}<\mathrm{MaF}$ & $\begin{array}{l}\mathbf{0 . 0 2} \\
\mathrm{IaF}\end{array}$ \\
\hline
\end{tabular}

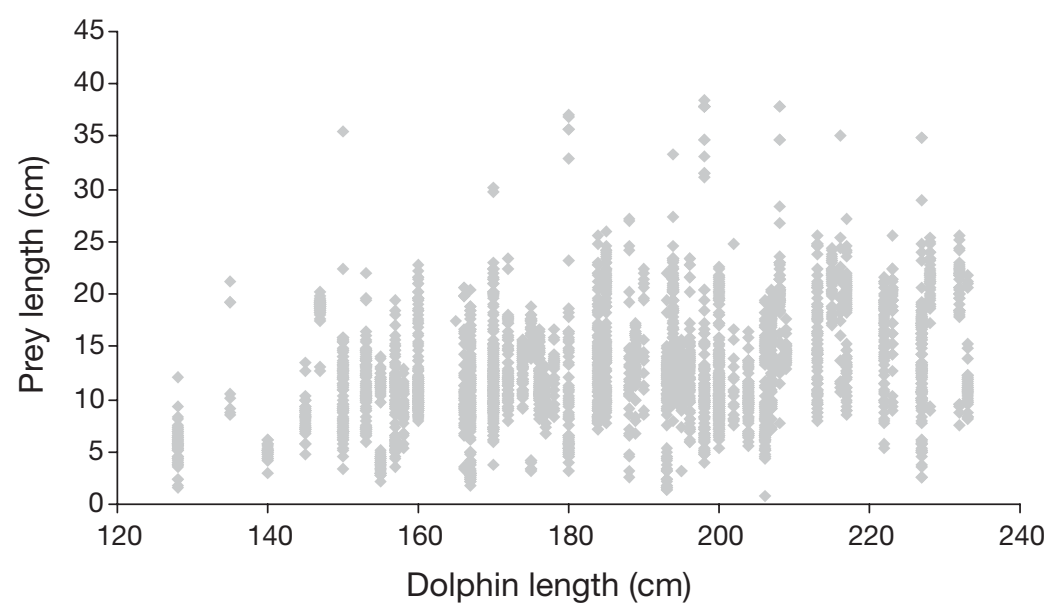

Fig. 3. Prey length in relation to dolphin length

\section{Overall diet of common dolphins}

Most previous studies on the food of the common dolphin reported on total diet instead of discriminating fresh versus digested fractions of the stomach content; consequently these previous studies must be compared to our total diet composition (Table 2). Common dolphins have been reported as feeding mainly on pelagic fish and consuming the most abundant prey in a particular region (Desportes 1985, Sekiguchi et al. 1992, Young \& Cockcroft 1994, Silva 1999, Santos et al. 2004a). Data from the present study broadly agree with previous findings: anchovy, sardine, horse mackerel and Trisopterus spp., which all form major components of total stomach contents (Table 2), are abundant fish of the Bay of Biscay (ICES 2004a). Several demersal and inshore species were found in the diet as prey of secondary importance (gobies, hake, sand smelt and sole). Although their contribution by mass was minor, gobies were the most frequent and abundant taxon in the present study, a fact not reported in previous studies. However, it is unclear if gobies were primary prey or prey of other fish secondarily eaten by the dolphins. In contrast to most other prey found here, gobies and soles are truly benthic species, possibly caught from discards produced in commercial fishing operations (Silva 1999).

Other studies in Europe also showed common dolphins preying mainly on the locally most abundant pelagic species. In the western English Channel, mackerel, sardine, Trisopterus spp., whiting and horse mackerel were the main prey found in stranded common dolphins (Kuiken et al. 1994, Gosselin 2001, De Pierrefond et al. 2005). The diet of 77 common dolphins stranded in the early 1980s in the Bay of Biscay was dominated by horse mackerel, Trisopterus spp. and blue whiting (Desportes 1985). Sardine and horse mackerel were found to be the most important prey eaten with the blue whiting in Galicia (Santos et al. 2004a), and off Portugal, Silva (1999) found that the most common prey of common dolphins were sardine 
Table 4. Delphinus delphis. Relative daily food intake and its variation (kg $\mathrm{d}^{-1}$ ) according to season and sex/maturity. Calorific values are from Harris \& Hislop (1978) (sandeel; sprat; blue whiting, gobie, hake and Trisopterus from whiting); Montevecchi et al. (1984) (mackerel; garfish from saury); C. Pusineri et al. (unpubl. data) (horse mackerel); Honda et al. (1992) (sardine); Rosen \& Trites (1999) (loliginid); values for anchovy and sepiolid were extrapolated from sardine and loliginid, respectively. Fish considered as fat are shaded

\begin{tabular}{|c|c|c|c|c|c|c|c|c|c|c|}
\hline \multirow{2}{*}{$\begin{array}{l}\text { Prey species } \\
\text { (calorific values } \\
\text { in } \mathrm{kJ} \mathrm{g}^{-1} \text { ) }\end{array}$} & \multirow{2}{*}{$\begin{array}{l}\text { Reference diet, } \\
\text { estimated from } \\
\text { all samples }\end{array}$} & \multicolumn{5}{|c|}{ Seasonal variation } & \multicolumn{4}{|c|}{$\begin{array}{l}\text { Variation according to } \\
\text { sex and maturity }\end{array}$} \\
\hline & & Winter & Spring & Summer & Autumn & $\% \mathrm{CV}$ & $\operatorname{Im}$ & MaM & $\mathrm{MaF}$ & $\% \mathrm{CV}$ \\
\hline \multicolumn{11}{|l|}{ Fish } \\
\hline Anchovy (9.6) & 0.61 & 0.57 & 1.06 & 0.40 & 0.75 & 40 & 0.94 & 0.31 & 0.38 & 64 \\
\hline Blue whiting (4.1) & 0.01 & 0.00 & 0.00 & 0.00 & 0.05 & 192 & 0.00 & 0.01 & 0.02 & 90 \\
\hline Garfish (6.8) & 0.03 & 0.05 & 0.00 & 0.00 & 0.00 & 200 & 0.00 & 0.00 & 0.11 & 173 \\
\hline Gobies (4.1) & 0.07 & 0.06 & 0.14 & 0.11 & 0.00 & 79 & 0.13 & 0.01 & 0.03 & 116 \\
\hline Hake (4.1) & 0.05 & 0.07 & 0.00 & 0.11 & 0.00 & 123 & 0.11 & 0.00 & 0.01 & 145 \\
\hline Horse mackerel (6.2) & 0.15 & 0.05 & 0.35 & 0.00 & 0.75 & 121 & 0.06 & 0.18 & 0.24 & 57 \\
\hline Mackerel (10.3) & 0.15 & 0.06 & 0.14 & 1.42 & 0.00 & 168 & 0.16 & 0.05 & 0.25 & 65 \\
\hline Trisopterus (4.1) & 0.02 & 0.03 & 0.01 & 0.04 & 0.00 & 92 & 0.06 & 0.00 & 0.00 & 173 \\
\hline Sandeel (6.5) & 0.05 & 0.03 & 0.01 & 0.00 & 0.00 & 155 & 0.05 & 0.00 & 0.09 & 96 \\
\hline Sardine (9.6) & 1.32 & 1.73 & 0.12 & 0.15 & 1.41 & 99 & 0.83 & 2.19 & 1.26 & 49 \\
\hline Sprat (10.9) & 0.26 & 0.07 & 0.91 & 0.36 & 0.01 & 122 & 0.37 & 0.00 & 0.34 & 87 \\
\hline \multicolumn{11}{|l|}{ Cephalopods } \\
\hline Loliginid (3.7) & 0.10 & 0.07 & 0.06 & 0.15 & 0.00 & 86 & 0.10 & 0.00 & 0.16 & 91 \\
\hline Sepiolid (3.7) & 0.09 & 0.13 & 0.02 & 0.05 & 0.00 & 114 & 0.19 & 0.01 & 0.01 & 157 \\
\hline Miscellaneous & 0.02 & 0.02 & 0.05 & 0.00 & 0.00 & 123 & 0.05 & 0.00 & 0.01 & 136 \\
\hline Total daily food intake & 2.93 & 2.94 & 2.87 & 2.79 & 2.97 & 3 & 3.05 & 2.76 & 2.91 & 5 \\
\hline $\begin{array}{l}\% \text { mass provided by } \\
\text { fat fish (shaded rows) }\end{array}$ & 79.8 & 82.7 & 77.6 & 83.3 & 73.3 & 6 & 75.5 & 92.6 & 76.6 & 12 \\
\hline $\begin{array}{l}\% \text { energy provided by } \\
\text { fat fish (shaded rows) }\end{array}$ & 89.3 & 91.3 & 87.9 & 92.9 & 81.3 & 6 & 88.3 & 95.3 & 85.6 & 6 \\
\hline
\end{tabular}

and blue whiting, known as common species in local waters. Finally, in the oceanic area off the Bay of Biscay, common dolphins fed mainly on myctophids, mostly Notoscopelus kroeyeri, and oceanic cephalopods like Teuthowenia megalops and Gonatus steenstrupi (Pusineri et al. 2007). The prey species assemblages observed in these oceanic common dolphins and the nearby neritic ones (present study) are thus completely different, reflecting the locally most abundant prey type. The stomach contents of the dolphins in the present study are likely to come from individuals feeding solely within the limits of the continental shelf, as only 6 individual prey among 11000 examined prey items were oceanic prey (squids belonging to the family Ommastrephidae). However, no telemetry data are available yet on movement and foraging strategy of the common dolphin within the Bay of Biscay.

\section{Dietary variation}

\section{Long-term variation}

Comparing long-term observations of dietary differences in common dolphins with trends in fish stocks indicates how the dolphin diet would reflect prey availability. In the Bay of Biscay, Desportes (1985) investigated the common dolphin diet from stranded dolphins collected from 1980 to 1984. By comparison with our results (dolphins from 1999 to 2002), the main trend in diet composition is the higher proportion of sardine and anchovy in 1998 to 2002 compared to the early 1980s and the lower contribution of hake, sand smelt and Trisopterus spp. No difference was noticed for horse mackerel and blue whiting. ICES reports indicate that sardine spawning stock biomass (SSB) in the area has increased since the mid-20th century and SSB for anchovy in 1987 was notably lower than from 1998 to 2002 (ICES 2004a). Hake SSB in the northern part of the area has been severely reduced from 1978 to present (ICES 2005). No trend between the 2 periods appears in the SSB of blue whiting and horse mackerel (ICES 2004a,b).

Hence fish stocks trends are in general agreement with trends observed in the diet of common dolphins over the same period. Santos et al. (2004a) also showed that the importance of 2 of the main prey in common dolphin diet in Galician waters (blue whiting and sardine) was related to the abundance of these fish species.

\section{Seasonal variation}

Seasonal differences in the importance of prey categories were clearly identified (Fig. 2, Table 3). Sardine was dominant by mass and sprat absent in the autumn and winter diets. In the summer, larger mackerels were 
eaten, leading to their seasonally high contribution by mass, and horse mackerel and gobies were absent in the summer and the autumn, respectively. Most of these seasonal variations could be related to the combination of changes in both dolphin and fish distributions. The common dolphin in the Bay of Biscay is thought to migrate from the coast to more offshore areas for reproduction (Evans 1980), but data supporting this are still rather sparse. Sardine has been reported to spawn from October to May with a peak in spring in the Cantabrian Sea (Solá et al. 1990). Spawning of sardine occurs along the shelf without clearly defined spawning grounds; thus, this resource seems accessible to dolphins year round on the continental shelf of the Bay of Biscay. Like sardine, anchovy is homogeneously distributed (J. Massé pers. comm.). Horse mackerel would migrate from the slope to the coast in the summer (Quéro 1984) and in the reverse direction in the autumn. Sprat is distributed near the coast and mostly in front of the Gironde and Loire estuaries (J. Massé pers. comm.); due to its patchy distribution, its presence in the diet would therefore be a good indicator of dolphin presence in large river plumes. The highest amount of sprat eaten was observed in spring, when half of the stomach samples contained sprat.

Sex- and maturity-related variation

Intraspecific differences in the diet of distinct sex and size categories have often been used to make inferences on the composition of dolphin schools during foraging activities (Young \& Cockcroft 1994, Silva 1999). In the present study, immature dolphins and mature males and females ate the same gross prey array, but mature males showed a less diversified diet, with a stronger dominance of sardine (Fig. 2). These results suggest that immature dolphins and mature males and females forage in similar areas, and the differences in prey proportions are probably dependent on their respective energetic needs and foraging skills. The results on prey size indicate that juveniles selected a smaller size range for sardine and horse mackerel (Table 3B). However, this trend did not appear in the other dominant prey species, whose size distributions were similar irrespective of the maturity or sex of the dolphins. Nevertheless, sizes of all prey together were correlated, albeit weakly, to predator length (Fig. 3).

\section{Effects of variation in dietary composition on estimated daily consumption}

Most of the published food consumption models integrating dietary variation were constructed for pinniped studies. Shelton et al. (1997) studied the variation of each parameter (population size, residency time, energetic requirements and diet) in a food consumption model of harp seals in the Gulf of St. Lawrence, to quantify the major sources of uncertainty; uncertainty in diet composition had the greatest effect on food consumption estimates. In the northeast Atlantic, dietary variation has been assessed and included in food consumption models for the most common pinnipeds (e.g. Hammond et al. 1994, Brown et al. 2001), but for cetaceans, this has only been assessed in common dolphins and porpoises in Galician and Scottish waters, respectively (Santos et al. 2004a,b).

Concerning the common dolphin, our results and those of previous studies (Young \& Cockcroft 1994, Santos et al. 2004a) showed temporal and sex-/maturity-related changes in the diet, which could potentially affect significantly the estimation of daily food intake as a result of variation in average energy content of the diet. The main result of the present study was that despite extensive changes in the proportion of most prey species according to years, seasons or sex-/ maturity-categories, the overall daily food intake changed little; changes in dietary composition tended to operate at a fairly constant and high rate of fat fish in the diet. There is little literature supporting this hypothesis of prey selection in delphinids that would be driven by body composition and energy content of the prey. However, Santos et al. (2004a) suggested that in the context of the optimal foraging theory, dolphins should select more energy-rich fish species, thereby maximizing their rate of energy intake. One could modulate this general consideration by incorporating prey energy content as an integral part of the common dolphin foraging strategy. Indeed, the foraging behaviour of the common dolphin is supposed to be generally highly active and cooperative, with some individuals maintaining the school of pelagic fish in dense balls, while others feed upon it. This kind of pelagic foraging would likely be more energy expensive than other strategies and would be more cost effective when targeting fat fish rather than equally available and abundant lean fish.

Acknowledgements. This work took place at the Centre de Recherche sur les Mammifères Marins (CRMM, La Rochelle) in collaboration with the University of La Rochelle, France. Financial support was provided by the EC funded project BIOCET (EVK3-CT-2000-00027). We are particularly grateful to members of the French Stranding Scheme and the whole staff of CRMM for providing the samples. Ages and reproductive status were determined by W. Dabin (CRMM). Thanks also to J. C. Quéro (Muséum d'Histoire Naturelle, La Rochelle, France), who identified the prey specimens of the reference collection, and to J. Massé (IFREMER, Nantes, France), who provided information on fish distributions in the Bay of Biscay. 


\section{LITERATURE CITED}

Bedford BC, Woolner LE, Jones BW (1986) Length-weight relationships for commercial fish species and conversion factors for various presentations. Fish Res Data Rep 10, Ministry of Agriculture, Fisheries and Food, Fisheries Laboratory, Lowestoft

Bjørge A, Bekkby T, Bakkestuen V, Framstad E (2002) Interactions between harbour seals, Phoca vitulina, and fisheries in complex coastal waters explored by combined Geographical Information System (GIS) and energetics modelling. ICES J Mar Sci 59:29-42

Brown EG, Pierce GJ, Hislop JRG, Santos MB (2001) Interannual variation in the summer diets of harbour seals Phoca vitulina at Mousa, Shetland (UK). J Mar Biol Assoc UK 81:325-337

Clarke MR (1986) A handbook for the identification of cephalopod beaks. Clarendon Press, Oxford

Collet A (1981) Biologie du dauphin commun Delphinus delphis L. en Atlantique nord-est. PhD dissertation, Université de Poitiers

Coull KA, Jermyn AS, Newton AW, Henderson GI, Hall WB (1989) Length/weight relationships for 88 species of fish encountered in the North East Atlantic. Scottish Fisheries Research Report 43, Department of Agriculture and Fisheries for Scotland

De Pierrefond JF, Dubois B, Desormonts S, Santos MB, Robin JP (2005) Stomach contents of English Channel cetaceans stranded on the coast of Normandy. J Mar Biol Assoc UK 85:1539-1546

Desportes G (1985) La nutrition des Odontocètes en Atlantique Nord-Est (cotes Françaises - îles Faeroe). PhD dissertation, Université de Poitiers

Dytham C (1999) Choosing and using statistics: a biologist's guide. Blackwell Science, Oxford

Evans PGH (1980) Cetaceans in British waters. Mamm Rev 10:1-52

Evans WE (1994) Common dolphin, white-bellied porpoise Delphinus delphis Linnaeus, 1758. In: Ridgway SH, Harrison RJ (eds) Handbook of marine mammals, Vol 5. Academic Press, London, p 191-224

Gosselin MP (2001) Aspects of the biology of common dolphins (Delphinus delphis) subject to incidental capture in fishing gears in the Celtic Sea and Channel. MS dissertation, Heriot-Watt University, Edinburgh

Hammill MO, Stenson GB (2000) Estimated prey consumption by harp seals (Phoca goenlandica), hooded seals (Cystophora cristata), grey seals (Halichoerus grypus) and harbour seals (Phoca vitulina) in Atlantic Canada. J Northw Atl Fish Sci 26:1-23

Hammond PS, Hall AJ, Prime JH (1994) The diet of grey seals around Orkney and other island and mainland sites in north-eastern Scotland. J Appl Ecol 31:340-350

Härkönen TJ (1986) Guide to the otoliths of the bony fishes of the Northeast Atlantic. Danbui ApS, Hellerup

Harris MP, Hislop JRG (1978) The food of young puffins Fratercula arctica. J Zool Lond 185:213-236

Honda S, Wada T, Matsubara T (1992) Relationship between food consumption and growth of Japanese sardine Sardinops melanostictus in the laboratory. Bull Fac Fish Hokkaido Univ 56:1-6

ICES (2004a) Report of the working group of the assessment of mackerel, horse mackerel, sardine and anchovy. ICES CM 2005/ACFM:08

ICES (2004b) Report of the working group of the northern pelagic and blue whiting fisheries. ICES CM 2004/ ACFM:24

Editorial responsibility: Otto Kinne,

Oldendorf/Luhe, Germany
ICES (2005) Report of the working group of the assessment of southern stocks of hake, monk and megrim. ICES CM 2005/ACFM:02

Kleiber M (1975) The fire of life: an introduction to animal energetics. Robert E. Krieger Publishing, New York

Kuiken T, Simpson VR, Allchin CR, Bennett PM and others (1994) Mass mortality of common dolphins (Delphinus delphis) in south west England due to incidental capture in fishing gear. Vet Rec 134:81-89

Montevecchi WA, Ricklefs RE, Kirkham IR, Gabaldon D (1984) Growth energetics of nestling northern gannets (Sula bassanus). Auk 101:334-341

Page B, McKenzie J, Goldsworthy SD (2005) Dietary resource partitioning among sympatric New Zealand and Australian fur seals. Mar Ecol Prog Ser 293:283-302

Pierce GJ, Boyle PR (1991) A review of methods for diet analysis in piscivorous marine mammals. Oceanogr Mar Biol Annu Rev 29:409-486

Pusineri C, Magnin V, Meynier L, Spitz J, Hassani S, Ridoux V (2007) Food and feeding ecology of the common dolphin (Delphinus delphis) in the oceanic northeast Atlantic and comparison with its diet in neritic areas. Mar Mamm Sci 23:30-47

Quéro JC (1984) Les poissons de mer des pêches françaises. Grancher, Paris

R Development Core Team (2005) R: a language and environment for statistical computing. R Foundation for Statistical Computing, Vienna, available at: www.r-project.org

Reynolds JC, Aebischer NJ (1991) Comparison and quantification of carnivore diet by faecal analysis: a critique, with recommendations, based on a study of the fox Vulpes vulpes. Mamm Rev 21:97-122

Rosen DAS, Trites AW (1999) Metabolic effects of low-energy diet on Steller sea lions, Eumatopias jubatus. Physiol Biochem Zool 72:723-731

Santos MB, Pierce GJ, López A, Martínez JA and others (2004a) Variability in the diet of common dolphins (Delphinus delphis) in Galician waters 1991-2003 and relationships with prey abundance. ICES CM 2004/Q:09

Santos MB, Pierce GJ, Reid RJ, Ross HM, Patterson IAP, Reid DG, Peach K (2004b) Variability in the diet of harbour porpoises (Phocoena phocoena) in Scottish waters 1992-2003. Mar Mamm Sci 20:1-27

Sekiguchi K, Klages NTW, Best PB (1992) Comparative analysis of the diet of smaller odontocete cetaceans along the coast of Southern Africa. S Afr J Mar Sci 12: 843-961

Shelton PA, Warren WG, Stenson GB, Lawson JW (1997) Quantifying some of the major sources of uncertainty associated with estimates of harp seal prey consumption. Part II: uncertainty in consumption estimates associated with population size, residency, energy requirement and diet. J Northw Atl Fish Sci 22:303-315

Silva MA (1999) Diet of common dolphins, Delphinus delphis, off the Portuguese continental coast. J Mar Biol Assoc UK 79:531-540

Solá A, Motos L, Franco C, Lago A (1990) Seasonal occurrence of pelagic fish eggs and larvae in the Cantabrian sea (VIIIc) and Galicia (IXa) from 1987 to 1989. ICES $\mathrm{CM} / \mathrm{H}: 25$

Young DD, Cockcroft VG (1994) Diet of common dolphins (Delphinus delphis) off the south-east coast of southern Africa: Opportunism or specialization? J Zool Lond 234: 41-53

Young RF, Phillips HD (2002) Primary production required to support bottlenose dolphins in a salt marsh estuarine creek system. Mar Mamm Sci 18:358-373

Submitted: July 26, 2006; Accepted: September 12, 2007

Proofs received from author(s): January 30, 2008 